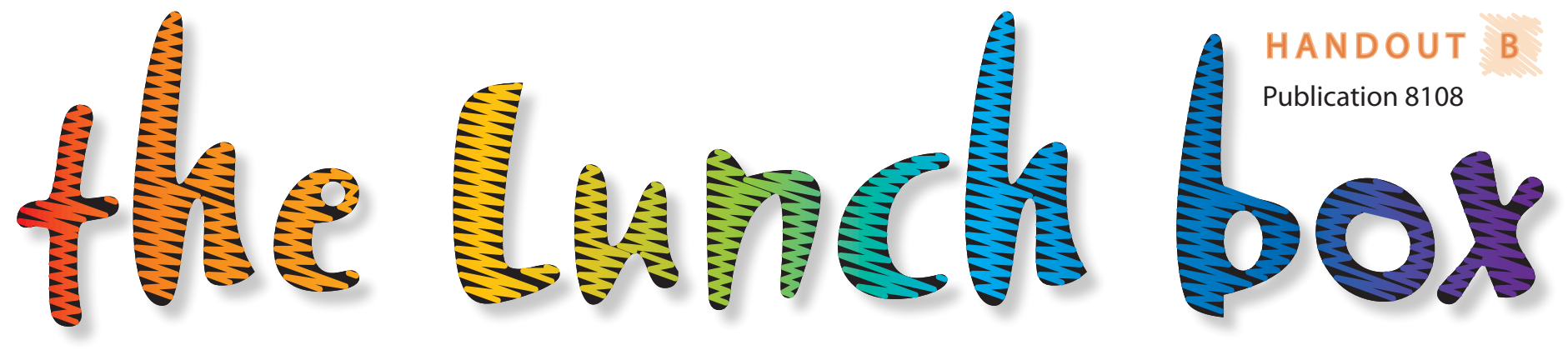

\title{
LEARNING FROM LABELS
}

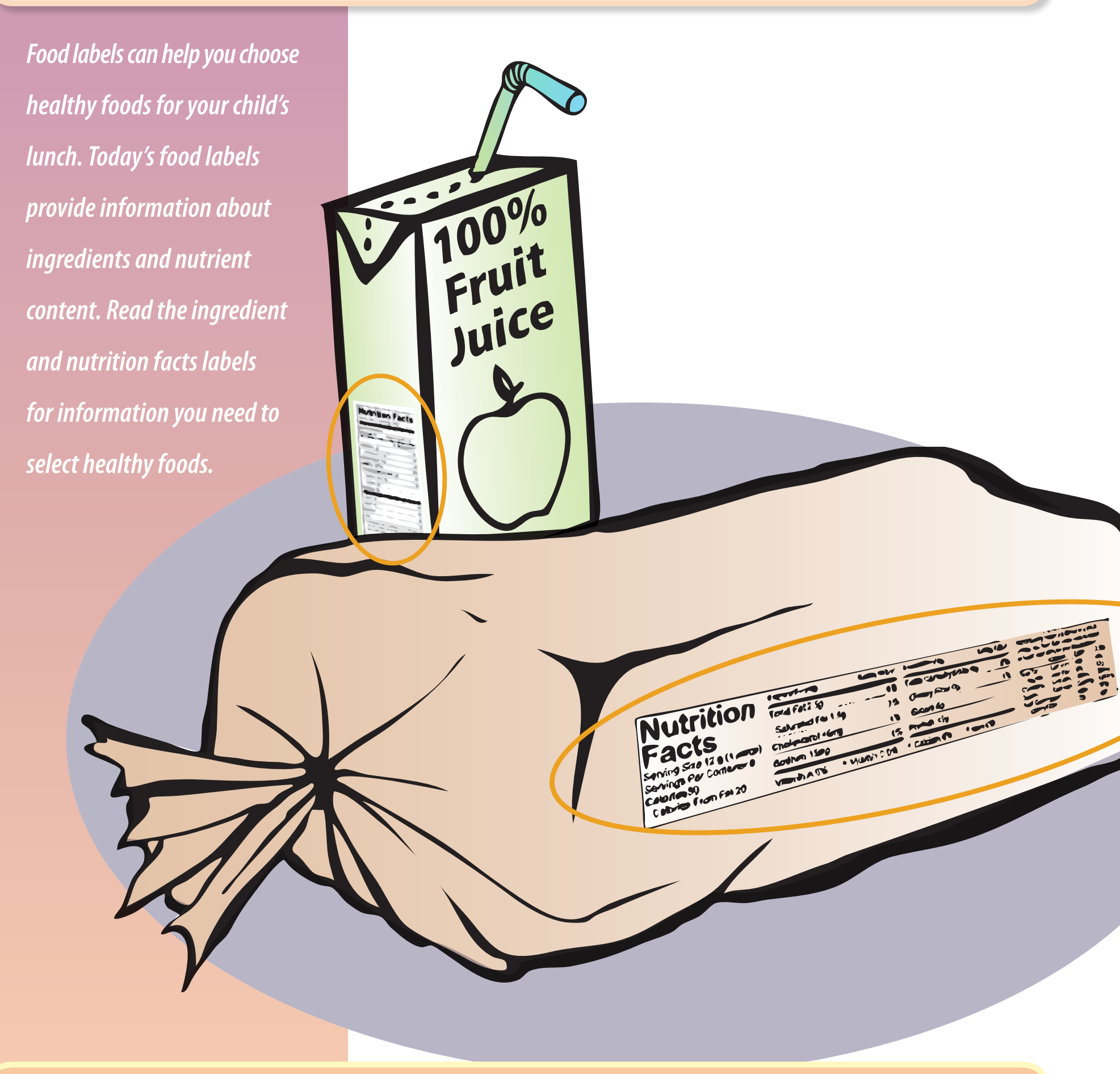




\section{Ingredient Labels}

Ingredient lists tell you what is really in the products you buy.

By law, food packages must list all of the ingredients in a product. This information is always printed on the outside of the package.

Food ingredients are listed according to the amount of each ingredient in the package. The ingredient that weighs the most is listed first, and the ingredient that weighs the least is listed last.

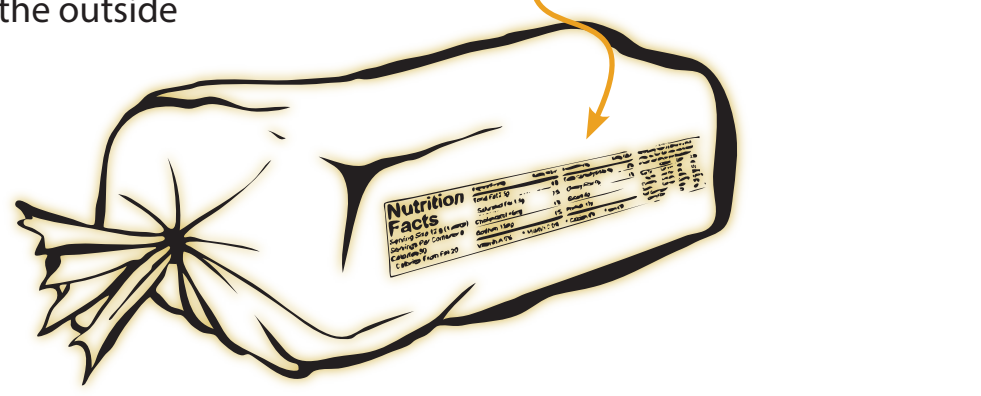

Look at this ingredient label from a loaf of wholewheat bread:

Ingredients: whole wheat flour, water, wheat gluten, brown sugar, molasses, soybean oil, honey, yeast, salt, cultured wheat starch, oats, soy flour, dough conditioners.

Compare this ingredient label from a loaf of wheat bread:

Ingredients: enriched wheat flour, water, highfructose corn syrup, wheat bran, soybean oil, molasses, wheat gluten, salt, whey, calcium sulfate, dough conditioners.

If you want whole grain bread, which loaf do you choose?

You would choose the first loaf, since it is made mainly of whole wheat flour. The second loaf contains mostly enriched wheat flour, which is commonly known as white flour.

Some wheat breads do contain a small amount of whole grain flour. The whole grain flour is usually listed as the third or fourth ingredient, which means that only a small amount was used.

Hint: When the ingredient list is very long, the first two or three ingredients usually make up most of the product.

\section{\% Daily Value}

The \% Daily Value column in the Nutrition Facts label shows whether a food is high or low in nutrients. A 5\% Daily Value or lower means that the food provides a small amount of the nutrient. A food with a $20 \%$ Daily Value or higher gives a large amount of the nutrient.

Use \% Daily Value to select foods that are low in fat, saturated fat, cholesterol, and sodium and to select foods that are high in fiber, vitamins, and minerals.

\section{A Quick Guide to} \% Daily Value

- $5 \%$ or less is low

- $20 \%$ or more is high

Note: Although this label is based on adult needs, it can be used as a general guide for small children.

\section{Nutrition Facts} Serving Size $1 / 2$ cup (114g) Servings Per Container 4

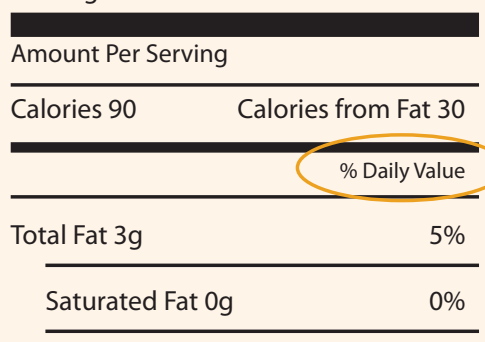

Trans Fat 0g

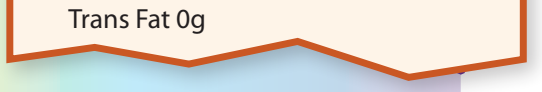




\section{Confused about Whole Wheat versus Wheat?}

Whole wheat bread has the entire wheat kernel and all of the nutrients that naturally occur in wheat, including fiber and micronutrients. The natural color of the wheat kernel contributes to the brown coloring of the bread.

Wheat bread contains mainly enriched white flour. Only part of the wheat kernel is used to make this flour. This flour has been enriched to replace the major nutrients lost during milling. The minor nutrients and fiber are not replaced. The brown color of wheat bread comes from other ingredients, such as molasses.
Today's nutrition experts recommend eating more whole grains to increase our intake of dietary fiber. Diets that are high in fiber may help reduce the risk of some types of cancers and can help lower cholesterol levels.

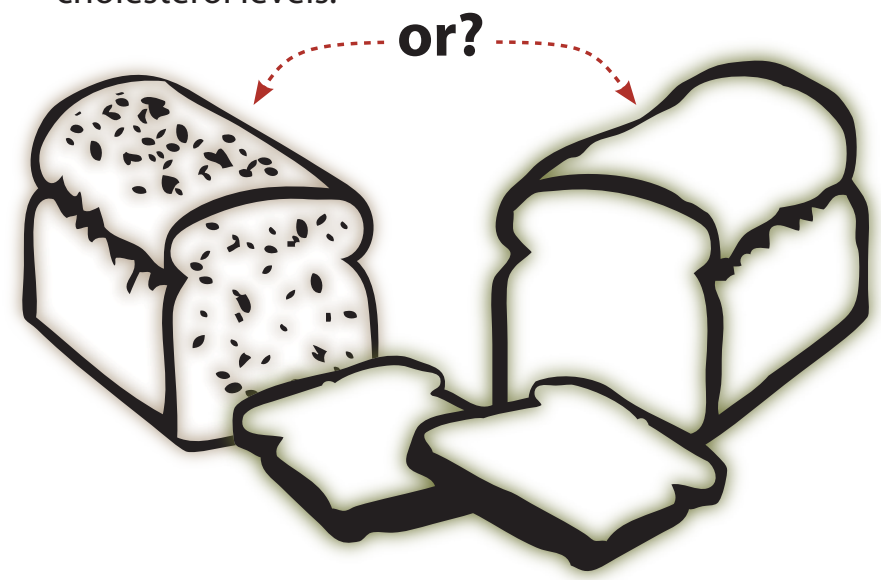

\section{Healthy Lunch Ideas}

$1 / 2$ tuna sandwich on whole-wheat bread

(made with reduced-fat mayonnaise)

Mini pretzels

Small green salad

Low-fat milk

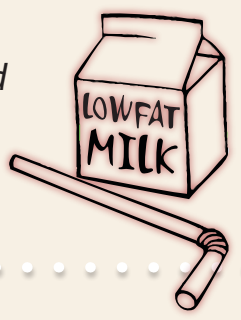

\section{Here's a fun meal that your child} can help make!

Homemade trail mix (recipe at right)

Carrot sticks Low-fat milk

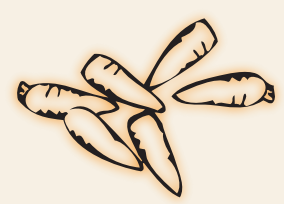

Unsweetened, ready-to-eat cereal Low-fat milk

$1 / 2$ banana

Fresh green beans

Water

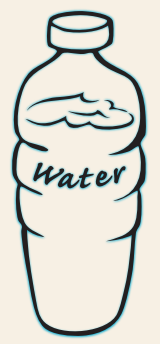

\section{Homemade Trail Mix}

$1 / 4$ cup toasted oat cereal

2 tablespoons raisins or chopped dried fruit

1 tablespoon sunflower seeds (without shells)

5 pretzel sticks

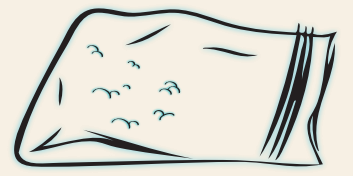

Place all ingredients in a small, plastic zipper bag. Seal the bag and shake. 
HANDOUT B

the lunch box

PAGE 4

Is It Fruit Juice or a Fruit Drink?

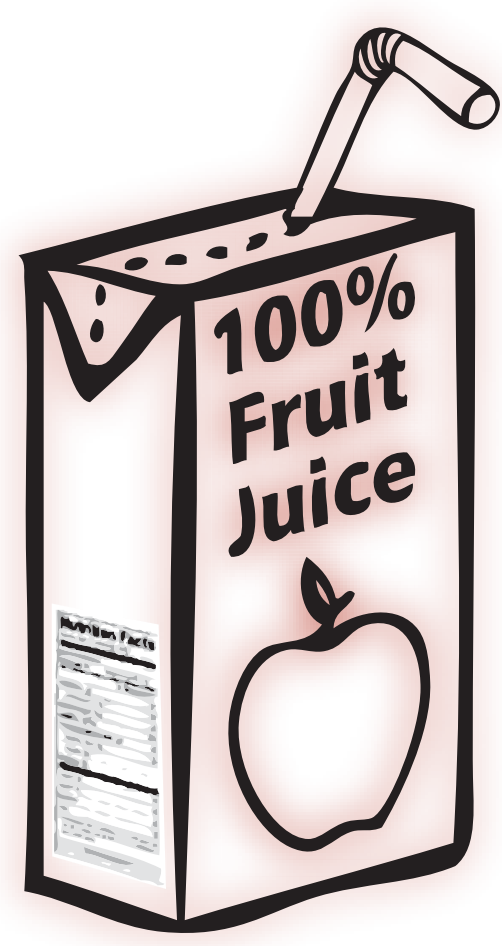

Fruit bits
Is a beverage real fruit juice or is it an imitation fruit drink? Use the label to find out.

A juice product that states " $100 \%$ juice" is made only from fruit juice. This product contains the nutrients that naturally occur in the fruit.

Fruit drinks, fruit-ades, and fruit punches are made mainly of sugar and water. Read the label to learn how much juice is in a product. Most fruit drinks contain less than $10 \%$ juice. Fruit drinks may be fortified with one or two of the major vitamins, but they do not have all of the nutrients found in real juice.

For best health, limit $100 \%$ fruit juice to no more than 4-6 oz daily for preschool children.

Real fruit

Healthy-Sounding Names

Many foods have healthy-sounding names. Products like fruit bits, fruit rolls, and fruit snacks sound like they are made of fruit. But they are really a form of candy made mainly of sugar, with a small amount of fruit juice concentrate. Don't be fooled by these product names! Put real fruit instead of "fruit snacks" in your child's lunch.

Fruit rolls

Fruit bits
Fruit snacks

Fruit snacks

Real fruit 


\section{the lunch box}

\section{PAGE 5}

\section{Granola Bar or Candy Bar?}

Here are the first few ingredients on a food label:

Milk chocolate (made from sugar, cocoa butter, chocolate, lactose, skim milk, milkfat, soy lecithin, artificial flavor), peanuts, corn syrup, sugar ...

\section{Is this label from a granola bar or a candy bar?}

It's from a candy bar.

These are the first ingredients of another product:

Milk chocolate (made from sugar, cocoa butter, chocolate, lactose, skim milk, milkfat, soy lecithin, vanillin), peanuts, corn syrup, sugar, milk...

\section{Is this label from a granola bar or a candy bar?}

It's from a granola bar.

Many granola bars have ingredients similar to those of candy bars.

Nutritionally, most granola bars and candy bars offer calories mainly from fat and sugar, but little in the way of other nutrients.

\section{DID YOU [KNOW:}

Sugar has many names. Ingredient labels may list sugar in these ways:

- corn syrup

- malto-dextrin

- honey

- corn sweeteners

- molasses

- high-fructose corn syrup

- natural sweetener

- invert sugar
- sugar

- brown sugar

- any ingredient name ending in - ose (such as dextrose, lactose, and fructose)
How many sugars are in the following ingredient list?

Unbleached wheat flour, butter, sugar, corn syrup, eggs, dextrose, nonfat milk, baking soda, cream of tartar

Answer: Three: Sugar, corn syrup, and dextrose. 


\section{Nutrition Facts Label}

The Nutrition Facts label can help you select healthy foods. This label states the nutritional value in a single serving of the product. It also shows how this food fits into the overall daily diet. For each serving of the product, the label gives the:

- serving size

- amount of fat, cholesterol, and sodium

- amount of carbohydrates, including fiber and sugar

- amount of protein

- amount this food provides of the daily needs for vitamin A, vitamin C, calcium, and iron (some labels list additional nutrients in this section)

The Nutrition Facts label makes it easy to compare two or more products. Let's look at how the Nutrition Facts label can be used to choose a lower-fat alternative to regular potato chips:

\begin{tabular}{|c|c|}
\hline \multicolumn{2}{|l|}{ Amount Per Serving } \\
\hline \multirow[t]{2}{*}{ Calories 90} & ies from Fat 30 \\
\hline & $\%$ Daily Value \\
\hline Total Fat 3g & $5 \%$ \\
\hline Saturated Fat 0g & $0 \%$ \\
\hline \multicolumn{2}{|l|}{ Trans Fat 0g } \\
\hline Cholesterol 0mg & $0 \%$ \\
\hline Sodium $300 \mathrm{mg}$ & $13 \%$ \\
\hline Total Carbohydrate $13 \mathrm{~g}$ & $4 \%$ \\
\hline Dietary Fiber $3 \mathrm{~g}$ & $12 \%$ \\
\hline \multicolumn{2}{|l|}{ Sugars $3 g$} \\
\hline \multicolumn{2}{|l|}{ Protein $3 g$} \\
\hline Vitamin A 80\% & Vitamin C 60\% \\
\hline Calcium 4\% & Iron $10 \%$ \\
\hline
\end{tabular}

Regular Potato Chips

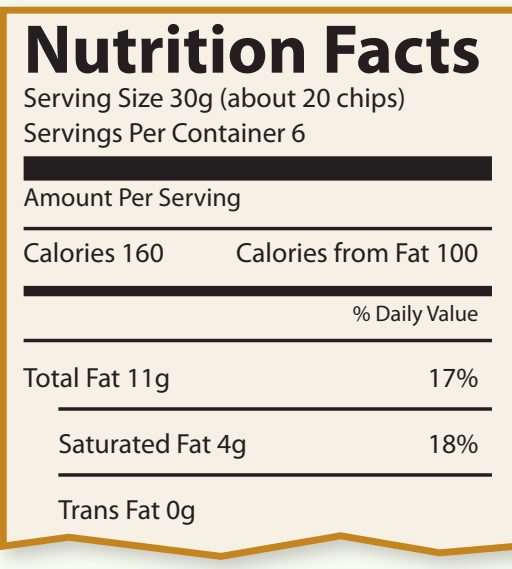

Baked Potato Chips

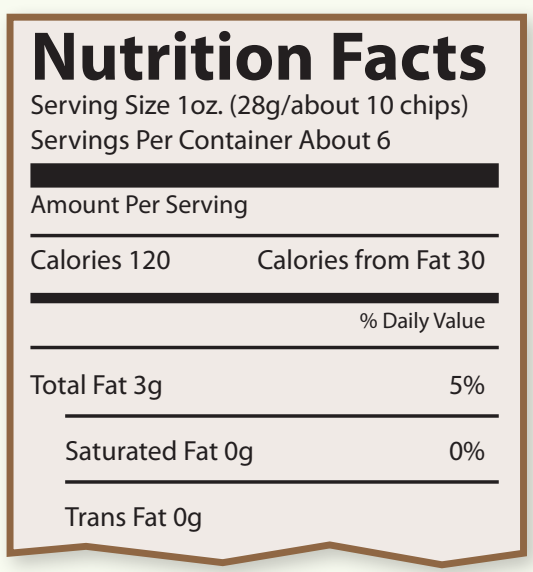

Mini Pretzel Twists

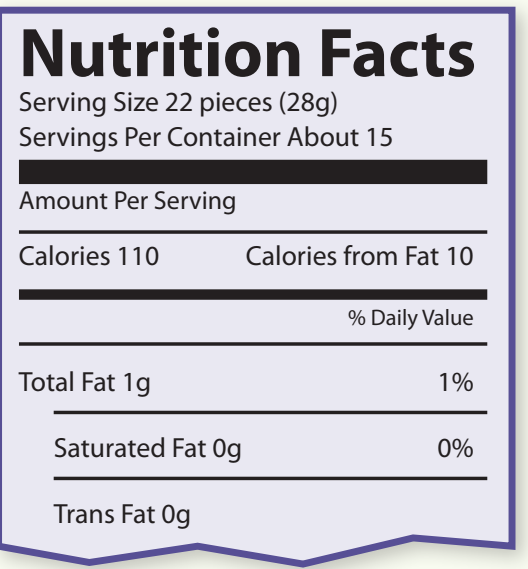

The Nutrition Facts labels indicate one serving of each product is similar in size -28 to 30 grams.

- This serving size of regular potato chips has 160 calories and 11 grams of fat.

- A similar serving size of baked potato chips has 120 calories and only 3 grams of fat.

- A serving of the mini pretzel twists has 110 calories and 1 gram of fat. 


\section{More Information}

More information on understanding and using food labels can be found at http://vm.cfsan.fda.gov/label.html.

The Lunch Box is a series of handouts designed for parents who pack lunches for their preschool children. The goal of these handouts is to assist parents in packing lunches that are nutritious, safe, and appealing for preschool children.

The author acknowledges the cooperation of the San Luis Obispo County preschools that assisted in the development of the Lunch Box program. This program was made possible by funds received from the First 5 Commission of San Luis Obispo County.

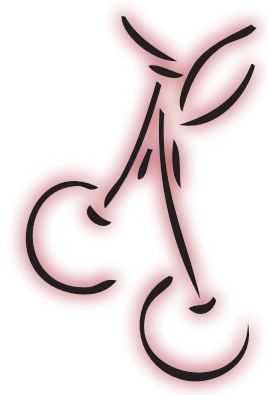

You will find related information in these titles and in other publications, slide sets, CD-ROMs, and videos from UC ANR:

Children and Weight: What's a Parent to Do?, DVD 6524D

EatFit Teacher's Curriculum, Publication 3424

Fit Families Novela Series, Publication 3496

To order these products, visit our online catalog at http:// anrcatalog.ucdavis.edu. You can also place orders by mail, phone, or FAX, or request a printed catalog of publications, slide sets, CD-ROMs, and videos from

University of California

Agriculture and Natural Resources

Communication Services

6701 San Pablo Avenue, 2nd Floor

Oakland, California 94608-1239

Telephone: (800) 994-8849 or (510) 642-2431,

FAX: (510) 643-5470

e-mail inquiries: danrcs@ucdavis.edu

An electronic version of this publication is available on the ANR Communication Services website at http://anrcatalog.ucdavis.edu.

\section{Publication 8108}

ISBN-13: 978-1-60107-518-5

\section{UC}

REVIEWED This publication has been anonymously peer reviewed for technical accuracy by University of California scientists and other qualified professionals. This review process was managed by the ANR Associate Editor for Nutrition and Food Safety.

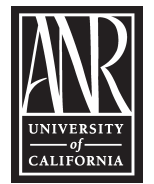

(C2007 by the Regents of the University of California Division of Agriculture and Natural Resources.

All rights reserved.

The University of California prohibits discrimination or harassment of any person on the basis of race, color, national origin, religion, sex, gender identity, pregnancy (including childbirth, and medical conditions related to pregnancy or childbirth), physical or mental disability, medical condition (cancer-related or genetic characteristics), ancestry, marital status, age, sexual orientation, citizenship, or status as a covered veteran (covered veterans are special disabled veterans, recently separated veterans, Vietnam era veterans, or any other veterans who served on active duty during a war or in a campaign or expedition for which a campaign badge has been authorized) in any of its programs or activities.

University policy is intended to be consistent with the provisions of applicable State and Federal laws.

Inquiries regarding the University's nondiscrimination policies may be directed to the Affirmative Action/Staff Personnel Services Director, University of California, Agriculture and Natural Resources, 1111 Franklin Street, $6^{\text {th }}$ Floor, Oakland, CA 94607, (510) 987-0096. For information about obtaining this publication, call (800) 994-8849. For downloading information, call (530) 297-4445.

pr-12/07-WJC/RW

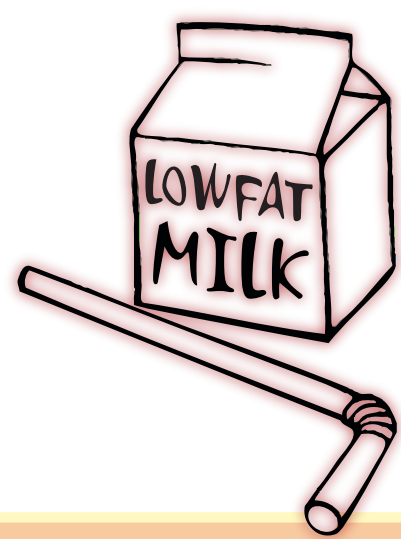

